Article

\title{
The Mediating Effect of Coping Strategies on Religious/Spiritual Struggles and Life Satisfaction
}

\author{
Małgorzata Szcześniak *(D), Zdzisław Kroplewski and Roman Szałachowski \\ Faculty of Social Sciences, University of Szczecin, ul. Krakowska 69, 71-017 Szczecin, Poland; \\ zkrop@univ.szczecin.pl (Z.K.); romasz@op.pl (R.S.) \\ * Correspondence: malgorzata.szczesniak@usz.edu.pl
}

Received: 11 March 2020; Accepted: 13 April 2020; Published: 16 April 2020

check for updates

\begin{abstract}
A growing number of researchers are testing potential problematic forms of religiousness that denote anxieties regarding sacred matters. However, only a few studies have assessed how religious/spiritual struggle is associated with positive outcomes. Because people's coping responses to stressors are key determinants of their well-being, we expected that different coping strategies could be potential mediators between religious problems/tensions and life satisfaction. The research was conducted on a group of 744 Roman Catholics. We used the Religious Comfort and Strain Scale, Satisfaction with Life Scale, and Brief Coping Orientation to Problems Experienced (COPE) questionnaire. The outcomes show that religious comfort correlated positively with life satisfaction, while fear/guilt, negative emotions toward God, and negative social interactions surrounding religion correlated negatively with life satisfaction. Our research amplifies the understanding of the religious/spiritual struggles and life satisfaction relationship, mediated by "secular" coping strategies. It confirms that both religious and secular methods of experiencing different strains seem to coexist with multiple other strategies in the context of broadly understood life satisfaction.
\end{abstract}

Keywords: religious/spiritual struggles; life satisfaction; coping strategies; mediation

\section{Introduction}

Religion is an integral part of the lives of many people worldwide (Zhang et al. 2018) and has beneficial effects on their personal adaptation (Zarzycka and Zietek 2019). There is considerable literature that associates religion and spirituality with physical (Hill and Pargament 2003), mental (Krause 2003), and relational health (Marks and Dollahite 2011; Marks et al. 2019). Religion helps individuals cope with stressors (Koenig 2009), maintain a sense of control (Sasaki and Kim 2011), regain psychological balance after experiencing stress (Zinnbauer and Pargament 1998), find meaning in life (Pargament 1997), deal with a serious disease (Cassibba et al. 2014), and preserve social interactions (Páez et al. 2018). Research in this regard shows that the efficiency of religion or spirituality is bound to the degree to which it is combined with the person's existence (Pargament 2002). However, a growing number of findings also test possible problematic types of religiosity (Abu-Raiya et al. 2018), which denote difficulties, tensions, and strains regarding sacred matters (Exline et al. 2000; Wilt et al. 2019a, 2019b) and are often referred to as religious or spiritual (R/S) struggles.

$\mathrm{R} / \mathrm{S}$ strains may manifest in one's perceived relationship with God, interpersonal struggles with individuals or institutions with respect to religious issues, and intrapsychic confusion expressed through doubts about one's beliefs, sense of guilt after committing offenses, lack of ultimate meaning, and negative emotions (Exline et al. 2000; Wilt et al. 2019a). Although R/S struggles often appear to stem from stressful life events (Trevino et al. 2019), which are typically associated with higher levels of depression (Ellison et al. 2013; Vandecreek et al. 2004; Vasegh et al. 2012), anxiety (Abu-Raiya et al. 2015), alcohol problems (Stauner et al. 2019), post-traumatic stress disorder (Evans et al. 2018), suicidal 
ideation (2000), and increased risk of dying of a life-threatening illness (Pargament et al. 2001), there is empirical evidence that religious strains can be turning points in life (Wilt et al. 2019b) as well. In fact, recent work suggests that R/S struggles may be a font of well-being (Szcześniak et al. 2019; Zarzycka and Zietek 2019) and comfort (Van Tongeren et al. 2013). They may also be a determinant of spiritual growth (Exline et al. 2017; Park and Cohen 1993) and transformation (Wilt et al. 2019b). People may come out of R/S struggles with a deeper sense of self and individual strength (Wilt et al. 2019a).

While some studies have shown connections between religious comfort/struggle and different dimensions of well-being (Abu-Raiya et al. 2015; Currier et al. 2019; Krause et al. 2018; Park et al. 2011; Wilt et al. 2016, 2017), only a few have investigated what makes satisfaction increase or decrease during a religious strain experience (Zarzycka and Puchalska-Wasyl 2019). Although the mechanism linking religiosity with psychological adjustment still remains unclear (Parenteau et al. 2011) because this relationship is very complex (Hebert et al. 2006), some researchers have proven that mediators or moderators play an important role in this association (Zarzycka and Zietek 2019). For example, internal dialogical activity turned out to be a mediator of the association between R/S struggles and psychological well-being (Zarzycka and Puchalska-Wasyl 2019). Similarly, Szcześniak et al. (2019) confirmed that gratitude, which demonstrates itself as a willingness to identify the undeserved increase of value in one's experience, is important to life satisfaction from the perspective of religious strains. In other studies (Wilt et al. 2019a), meeting with the "sacred" (God, experience associated with the divine, transcendent reality) was related to an increase of positive outcomes at both the interindividual (social well-being) and intraindividual (personal well-being) levels.

Because people's coping reactions to stressful circumstances are determining factors of their well-being (Lazarus 1966), we expected that different secular coping strategies, also called non-religious (McDougle et al. 2016), could be potential mediators between religious problems/tensions and life satisfaction. Indeed, according to the Transactional Model of Stress and Coping (Lazarus and Folkman 1984), cognitive appraisals and behavioral efforts may change the relationship between a specific stressor and health, contributing to an alleviation or reduction of stress. Besides these theoretical considerations, a large body of cross-sectional and longitudinal studies furnish empirical proof for the mediatory effect of coping on stressful events and quality of life. For example, in their study of parents with autistic children, Dardas and Ahmad (2013) observed that accepting responsibility, conceptualized as the recognition of one's input to the problematic situation, was a mediator strategy in the relation between stress and quality of life. Similarly, in their research among caregiving spouses, Pruchno and Resch (1989) discovered that wishfulness and intrapsychic strategies mediated the association between stress and well-being, operationalized as anxiety and depression. Moreover, the coping process was found to mediate the hardiness-illness association (Williams et al. 1992).

So far, to our knowledge, only a few studies (Parenteau et al. 2011) have addressed whether different forms of secular coping strategies can likely be mediators of the connection between religious comfort/struggling and life satisfaction. As we chose a cross-sectional design to study this mediatory model, providing a substantial rationale, theoretical and/or based on empirical evidence, for the temporal ordering specifications of the examined variables is required (Szcześniak et al. 2019), specifically R/S struggles and life satisfaction, R/S struggles and coping strategies, and coping strategies and life satisfaction. First, a number of studies have shown that religious involvement is believed to promote and foster adolescent and adult well-being (Ferris 2002; Abu-Raiya et al. 2015; Salifu Yendork and Somhlaba 2017), the social dimension of quality of life (Idler et al. 2009), and life satisfaction (Sawatzky et al. 2005). In their meta-analysis of 51 studies, Sawatzky et al. (2005) found a moderate effect size of spirituality on quality of life ( $r=-0.34,95 \%$ CI: $0.28-0.40)$ among all age groups. On the other hand, persisting religious tensions with God or unresolved conflicts with other people over faith may negatively influence personal well-being (Mahoney and Cano 2014). Abu-Raiya et al. (2015) obtained significant negative correlations between R/S struggle subscales and the indices of well-being in a nationwide sample of adults. Second, some researchers have suggested that secular coping strategies may accompany R/S strains (McDougle et al. 2016). 
In turn, other theorists consider the way in which religion is involved in the coping process and contributes to the regulation of emotions (Pargament et al. 1990). Ai et al. (2007) suggested paying more attention to assessing the mediation of faith on health through considering secular mediators. Third, many findings have shown that active styles of coping in contrast to passive forms tend to have a beneficial effect on psychological outcomes (Baitar et al. 2018; Kim et al. 2010). Moreover, meaningful coping that consists of making sense of a stressful event may result in higher levels of life satisfaction (Dezutter et al. 2017). Pakenham (2008) argued that the coping response of recognition was linked to greater life satisfaction in the caretakers of people affected by multiple sclerosis.

Based on the literature, four hypotheses were formulated:

Hypothesis 1 (H1): Religious comfort resulting from confidence and a relationship with God is positively related to life satisfaction, while fear/guilt, negative emotions toward divinity, and negative social interactions concerning religion are associated negatively with life satisfaction.

Hypothesis 2 (H2): Religious comfort is positively connected to religious coping and secular coping strategies-active coping, planning, positive reframing, acceptance, humor, emotional support, and instrumental support-and negatively related to self-distraction, venting, behavioral disengagement, denial, and substance abuse.

Hypothesis 3 (H3): Fear/guilt, negative emotions toward God, and negative social interactions related to religion are negatively related to active coping, planning, positive reframing, acceptance, humor, emotional support, instrumental support, and religious coping and positively related to self-distraction, venting, behavioral disengagement, denial, substance abuse, and self-blame.

Hypothesis 4 (H4): Coping strategies mediate the effect on life satisfaction of religious comfort, fear/guilt, negative emotions toward God, and negative social interactions related to religion.

\section{Materials and Methods}

\subsection{Ethics Approval}

This research was approved by the Bioethics Committee of the Institute of Psychology at the University of Szczecin (KB N ${ }^{\circ}$ 10, 20.12.2018) and was conducted in conformity with the Declaration of Helsinki.

\subsection{Participants}

This research was conducted on a group of 744 Roman Catholics (51\% women). The mean age of the respondents was $\mathrm{M}=25.94$ with $\mathrm{SD}=11.322$ (range $=14-79$ years). Almost $10 \%$ of participants considered themselves to not be religious, $17 \%$-religious to a small extent, $16 \%$-religious to an average degree, $28 \%$ - quite religious, and 29\%—-very religious.

\subsection{Data Collection}

The participants were enrolled through online forums for Roman Catholics. Facebook group administrators were asked whether our online survey could be posted on their groups' pages, which associate members of this denomination. The reason this group of people was chosen is because Poland has a relatively homogeneous structure with respect to religion (Turska-Kawa and Wojtasik 2017), and there is little research on Roman Catholics with respect to this issue. All of the participants who decided to join the study were given comprehensive instruction about the research objectives and were asked to fill out a web-based informed consent. Adolescents below the age of 18 who were able to understand the purpose and the nature of the research provided a parental consent. Only after providing their consent were the participants allowed to complete the battery of questionnaires. 


\subsection{Assessment of the Religious Comfort and Strain Scale (RCSS)}

RCSS, developed by Exline and contributors (Exline et al. 2000) and adapted into Polish by Zarzycka (2014), is a questionnaire of 28 items that assesses four dimensions of religiosity: comfort, fear/guilt, negative emotions toward God, and negative social interactions surrounding religion. Religious comfort estimates perceiving faith as a source of meaning and strength. God is seen as caring and trustworthy ("You feel supported by God"). The subscale of fear and guilt measures the intensity of concern about one's own mistakes and transgressions and guilt resulting from one's sins ("You fear that God will condemn you for your mistakes"). The subscale of negative emotions toward God reflects feelings of abandonment by a God perceived as unjust and punishing ("You feel that God has let you down"). The subscale of negative social interactions indicates the adverse emotions toward fellow congregants or religious institutions ("You have bad memories of past experiences with religion or religious people"). Participants reply to each item on an 11-point Likert scale (from $0=$ not at all to $10=$ extremely). In the current research, the Cronbach's alpha value was good for fear/guilt $(\alpha=0.80)$, negative emotions toward God $(\alpha=0.84)$, and negative interactions surrounding religion $(\alpha=0.79)$ and excellent for religious comfort $(\alpha=0.98)$.

\subsection{Assessment of the Satisfaction with Life Scale (SWLS)}

SWLS, created by Diener et al. (1985) and adapted into Polish by Juczyński (2001), is the most frequently used instrument to measure one's life satisfaction as a whole. The participants estimate all five affirmations by employing multiple-choice answers on a 7-point Likert scale $(1=$ strongly disagree to $7=$ strongly agree). The higher the final score, the stronger the general satisfaction with life. The psychometric properties of this scale reported in distinct studies demonstrate a good coefficient Cronbach's alpha of 0.82 (Diener et al. 1985). In the current group, Cronbach's alpha was 0.85, thus confirming the good internal consistency of the scale.

\subsection{Assessment of the Coping Orientation to Problems Experienced (Brief COPE) Questionnaire}

Brief COPE, designed by Carver (1997) and adapted into Polish by Juczyński and Ogińska-Bulik (2009), is a multidimensional measure that serves to identify the nature of fourteen different coping strategies implemented by individuals in stressful situations of daily life: active coping, planning, positive reframing, acceptance, humor, emotional support, instrumental support, self-distraction, venting, behavioral disengagement, denial, substance abuse, self-blame, and religious coping. All subscales, besides religious coping, can be considered to be secular or non-religious strategies of coping. The questionnaire includes 28 items, scored from $0=$ "I haven't been doing this at all" to $3=$ "I've been doing this a lot". Higher scores reflect more engagement in a coping behavior. Cronbach's alpha for the Brief COPE in this sample was measured according to a second-order dimension. Dimensions that are generally qualified as adaptive (active coping, planning, positive reframing, acceptance, emotional support, instrumental support, and religiosity) had $\alpha=0.824$. Instead, dimensions that are considered to be less adaptive (self-distraction, venting, behavioral disengagement, denial, substance abuse, self-blame, and humor) had $\alpha=0.761$. Such results confirm that Brief COPE is a valid and psychometrically sound instrument for measuring coping strategies (García et al. 2018).

\subsection{Statistical Analysis}

All data analyses were carried out using SPSS statistical software (version 20, IBM). Missing data were not an issue in this investigation as each questionnaire of the battery had to be $100 \%$ completed prior to passing to the subsequent stage. The data distribution was examined by employing the measures of skewness and kurtosis. Correlations between variables were calculated to test the first three hypotheses.

An a priori G*Power 3.1.9.4 (Heinrich-Heine-Universität, Düsseldorf, Germany; Faul et al. 2007) analysis was conducted to determine the suitable sample size. We implemented the suggested higher 
power criteria of 0.95 (Lakens 2013) and a critical significance level of $\alpha$ of 0.05 to identify a small effect size of $\mathrm{f}^{2}=0.015$. Because there were no former investigations on the links between religious strains, life satisfaction, and secular coping strategies as potential mediators, we used this $\mathrm{f}^{2}$ value. In fact, Cohen (1988) suggested that, in novel studies that cannot be compared to relevant previous results in the scientific works, such a benchmark is justified. The $G^{*}$ Power analysis with the abovementioned parameters would demand a sample of at least 723 participants.

We employed a linear regression to check for the existence of potential confounders and to verify whether they were not confusing the association between dependent and independent variables (Johnston et al. 2018). First, because the independent variables included in the model could highly correlate with each other, we conducted an index of tolerance and the measure of variance inflation factors (VIF) to detect collinearity. Second, we assessed the data for the cases of multivariate outliers by applying Mahalanobis' distance and Cook's distance. Third, the participants' sex, age, and subjective opinion about the intensity of their religiosity were added to monitor for their latent impact on the relationship between religious strains and life satisfaction. The probable confounding variables were entered at Step 1. All other variables supposed to be predictors of life satisfaction were introduced at Step 2.

The PROCESS macro in version 3.2 (Hayes 2013) was applied to control whether the fourteen dimensions of Brief COPE would mediate the relationship between religious comfort and three negative forms of strains and life satisfaction. Religious struggle acted as the independent variable and life satisfaction as the dependent variable. Active coping, planning, positive reframing, acceptance, humor, emotional support, instrumental support, self-distraction, venting, behavioral disengagement, denial, substance abuse, self-blame, and religious coping were treated as mediating variables (separately). Consequently, we analyzed fourteen single-level mediation models (Model no. 4), comprising three-variable systems. The bootstrap estimates and $95 \%$ confidence intervals (CI) for the indirect effects were gained through the procedure of 5000 bootstrapped samples.

\section{Results}

Variables concerning religious struggles, coping strategies, and life satisfaction were estimated for the degree of skewness and kurtosis indexes. According to the rule of thumb, we adopted values less than \pm 2 as a fairly normal distribution (Bachman 2004). Because only one value of kurtosis went over this limit of \pm 2 (Table 1), we considered our data to be normally distributed.

In line with our hypothesis (H1), religious comfort correlated positively with life satisfaction. Instead, fear/guilt, negative emotions toward God, and negative social interactions surrounding religion correlated negatively with life satisfaction (Table 2). Statistics showed that these associations were significant at $p$-values $<0.01$. In other words, it was demonstrated that respondents who display a greater faith in God experience reduced anxiety or remorse, do not perceive God as forsaking people, and do not have adverse emotions toward fellow congregants or religious institutions, declare higher life satisfaction. With respect to Hypothesis $\mathrm{H} 2$, religious comfort was positively connected to active coping, planning, positive reframing, acceptance, emotional support, instrumental support, and religious coping. Moreover, religious comfort negatively correlated with self-distraction, venting, behavioral disengagement, denial, substance abuse, self-blame, and humor. The only result that did not confirm the assumptions of Hypothesis $\mathrm{H} 2$ was the negative correlation between religious comfort and humor.

In terms of Hypothesis H3, the results largely confirmed our assumptions. Self-distraction, venting, behavioral disengagement, denial, substance abuse, self-blame, and religious coping correlated positively with negative dimensions of religious struggle. Active coping, positive reframing, and emotional support were negatively linked to three dimensions of religious strain. Planning and acceptance were negatively related to fear and negative emotions toward God. Humor was related negatively to negative emotions toward God and institutions. Instrumental support was associated 
negatively only with negative emotions toward God. Religious coping was associated positively with fear and negatively with negative emotions toward God and institutions.

Table 1. Descriptive statistics for the Religious Comfort and Strain Scale (RCSS), the Satisfaction with Life Scale (SWLS), and the Brief Coping Orientation to Problems Experienced (COPE) questionnaire $(\mathrm{N}=744)$.

\begin{tabular}{ccccc}
\hline Scales & M & SD & Skewness & Kurtosis \\
\hline LS & 4.139 & 1.408 & -0.213 & -0.631 \\
RC & 6.261 & 3.430 & -0.614 & -1.078 \\
FG & 3.043 & 2.128 & 0.464 & -0.367 \\
NG & 1.556 & 1.952 & 1.653 & 2.587 \\
NI & 4.372 & 2.167 & 0.356 & -0.636 \\
AC & 3.998 & 1.403 & -0.466 & -0.092 \\
PL & 4.309 & 1.432 & -0.620 & -0.126 \\
PR & 3.623 & 1.588 & -0.344 & -0.388 \\
AA & 4.165 & 1.365 & -0.562 & 0.225 \\
HU & 2.334 & 1.471 & 0.339 & -0.276 \\
ES & 3.560 & 1.766 & -0.403 & -0.676 \\
IS & 3.646 & 1.689 & -0.450 & -0.508 \\
SD & 3.232 & 1.632 & -0.192 & -0.674 \\
VE & 3.110 & 1.455 & -0.135 & -0.369 \\
BD & 1.762 & 1.496 & 0.624 & -0.101 \\
DE & 1.776 & 1.586 & 0.631 & -0.398 \\
SA & 1.236 & 1.813 & 1.349 & 0.684 \\
SB & 3.420 & 1.726 & -0.205 & -0.781 \\
RL & 3.142 & 2.242 & -0.179 & -1.422 \\
\hline
\end{tabular}

LS—life satisfaction; RC—religious comfort; FG—fear/guilt; NG—negative emotions toward God; NI—negative social interactions surrounding religion; $\mathrm{AC}$-active coping; $\mathrm{PL}$ - planning; $\mathrm{PR}$ - positive reframing; $\mathrm{AA}$-acceptance; HU—humor; ES — emotional support; IS—instrumental support; SD—self distraction; VE—venting; BD—behavioral disengagement; $\mathrm{DE}$-denial; SA—substance abuse; SB—self-blame; RL—religious coping.

In relation to the issue of multicollinearity and confounding variables, although some authors put the cut-off for VIFs at 10 or greater, we adopted in this research an index of 2.5, following Johnston and colleagues' (2018) suggestion that higher values might indicate considerable collinearity. At the same time, we assumed a tolerance value of less than 0.2 as a problem of a possible multicollinearity (Mehmeoglu and Jakobsen 2017). Considering that the examination of multiple regression produced a VIF of 1.01-2.39 and a tolerance rate of between 0.41 and 0.99 , multicollinearity indexes showed minor indication of multicollinearity for the current data. Mahalanobis' distance method was performed, employing the chi-square distribution with a highly robust estimate for a case being an outlier $(p<0.001)$ (Fidell and Tabachnick 2003). Only 21 of 744 cases were detected as suspected multivariate outliers. Despite this, because a reanalysis with the outliers removed showed minimal changes in correlations, regressions, and mediations, we chose to not remove them from the sample. Additionally, because our dataset was large enough, it matched the population from which it was taken, and the probability of outlying values increased (Osborne and Overbay 2004). In addition, Cook's value (between 0.000 and 0.025) was well below the point where the researcher should be concerned (less than 1) (Fidell and Tabachnick 2003), signifying that the cases were not potentially questionable with regard to holding an undue impact on the model. Hierarchical regression computations displayed that sex, age, and subjective opinion about the intensity of one's religiosity did not make a substantial input into the model, accounting for only $6 \%$ of the variance $\left(R^{2}=0.060\right)$ : $\operatorname{sex}(\beta=0.018, \mathrm{t}=0.601, p=0.548)$, age $(\beta=0.034, t=1.161, p=0.246)$, and the subjective opinion about the intensity of one's religiosity ( $\beta=0.041, t=0.929, p=0.353)$. The predictor variables explained a further $42.5 \%$ of the variance, in spite of monitoring for the effects of sex, age, and subjective opinion about the intensity of one's religiosity. 
Table 2. Correlation matrix between dimensions of religious struggle, life satisfaction, and coping strategies $(\mathrm{N}=744)$.

\begin{tabular}{|c|c|c|c|c|c|c|c|c|c|c|c|c|c|c|c|c|c|c|c|}
\hline & LS & RC & FG & NG & NI & AC & PL & PR & AA & $\mathrm{HU}$ & ES & IS & SD & VE & BD & $\mathrm{DE}$ & SA & SB & RL \\
\hline LS & 1 & & & & & & & & & & & & & & & & & & \\
\hline RC & $0.27 * *$ & 1 & & & & & & & & & & & & & & & & & \\
\hline FG & $-0.20^{* *}$ & $0.30^{* *}$ & 1 & & & & & & & & & & & & & & & & \\
\hline NG & $-0.34^{* *}$ & $-0.47 * *$ & $0.21 * *$ & 1 & & & & & & & & & & & & & & & \\
\hline NI & $-0.27^{* *}$ & $-0.43^{* *}$ & $0.09 *$ & $-0.50^{* *}$ & 1 & & & & & & & & & & & & & & \\
\hline AC & $0.36^{* *}$ & $0.11^{* *}$ & $-0.17^{* *}$ & $-0.21^{* *}$ & $-0.09 * *$ & 1 & & & & & & & & & & & & & \\
\hline PL & $0.34^{* *}$ & $0.08^{*}$ & $-0.17^{* *}$ & $-0.13^{* *}$ & -0.03 & $0.58^{* *}$ & 1 & & & & & & & & & & & & \\
\hline PR & $0.41^{* *}$ & $0.21^{* *}$ & $-0.13 * *$ & $-0.19^{* *}$ & $-0.12 * *$ & 0.34 ** & $0.40^{* *}$ & 1 & & & & & & & & & & & \\
\hline AA & $0.26^{* *}$ & $0.10^{* *}$ & -0.08 * & $-0.16^{* *}$ & -0.03 & $0.32^{* *}$ & $0.39 * *$ & $0.45^{* *}$ & 1 & & & & & & & & & & \\
\hline $\mathrm{HU}$ & $0.08^{*}$ & -0.10 ** & 0.04 & $0.08^{*}$ & $0.12 * *$ & 0.03 & 0.07 & $0.22 * *$ & $0.23 * *$ & 1 & & & & & & & & & \\
\hline ES & $0.43 * *$ & $0.14^{* *}$ & $-0.10^{* *}$ & $-0.14 * *$ & $-0.16^{* *}$ & 0.28 ** & $0.21 * *$ & $0.29 * *$ & $0.23 * *$ & $0.12 * *$ & 1 & & & & & & & & \\
\hline IS & $0.30^{* *}$ & $0.12 * *$ & -0.06 & $-0.08 *$ & -0.07 & 0.26 ** & $0.22 * *$ & $0.24 * *$ & $0.21 * *$ & 0.05 & $0.73 * *$ & 1 & & & & & & & \\
\hline SD & $-0.15^{* *}$ & $-0.13^{* *}$ & $0.11^{* *}$ & $0.19^{* *}$ & $0.17^{* *}$ & -0.02 & -0.05 & 0.04 & 0.01 & $0.14^{* *}$ & 0.05 & $0.08 *$ & 1 & & & & & & \\
\hline VE & $-0.08^{*}$ & $-0.09 *$ & $0.16^{* *}$ & $0.20 * *$ & $0.20^{* *}$ & -0.05 & -0.05 & -0.02 & -0.03 & $0.08^{*}$ & $0.13^{* *}$ & 0.20 ** & $0.34^{* *}$ & 1 & & & & & \\
\hline BD & $-0.41^{* *}$ & $-0.10^{* *}$ & $0.28^{* *}$ & $0.26^{* *}$ & $0.17^{* *}$ & $-0.54 * *$ & $-0.47^{* *}$ & $-0.31^{* *}$ & $-0.23^{* *}$ & 0.03 & $-0.25 * *$ & $-0.17^{* *}$ & 0.22 ** & $0.26^{* *}$ & 1 & & & & \\
\hline DE & $-0.19^{* *}$ & $-0.12 * *$ & $0.14 * *$ & $0.20 * *$ & $0.17^{* *}$ & $-0.15^{* *}$ & $-0.19^{* *}$ & -0.05 & $-0.14^{* *}$ & $0.08 *$ & -0.01 & -0.01 & $0.36^{* *}$ & $0.38 * *$ & $0.32 * *$ & 1 & & & \\
\hline SA & $-0.19^{* *}$ & $-0.16^{* *}$ & $0.17^{* *}$ & $0.22 * *$ & $0.21 * *$ & $-0.17^{* *}$ & $-0.17^{* *}$ & $-0.16^{* *}$ & $-0.12 * *$ & $0.14 * *$ & -0.07 & $-0.09 *$ & 0.18 ** & $0.17^{* *}$ & $0.23 * *$ & $0.22 * *$ & 1 & & \\
\hline SB & $-0.40^{* *}$ & -0.10 ** & $0.36 * *$ & $0.25 * *$ & $0.27^{* *}$ & $-0.21^{* *}$ & $-0.13^{* *}$ & $-0.25^{* *}$ & $-0.12 * *$ & -0.03 & $-0.22 * *$ & $-0.12 * *$ & $0.22 * *$ & $0.29 * *$ & $0.40 * *$ & $0.30^{* *}$ & $0.27^{* *}$ & 1 & \\
\hline RL & $0.23 * *$ & 0.85 ** & $0.26 * *$ & $-0.36^{* *}$ & $-0.35^{* *}$ & $0.14^{* *}$ & $0.13^{* *}$ & $0.23 * *$ & $0.11^{* *}$ & $-0.10^{* *}$ & $0.16^{* *}$ & 0.22 ** & -0.08 * & -0.02 & $-0.09 *$ & $-0.11^{* *}$ & $-0.16^{* *}$ & -0.03 & 1 \\
\hline
\end{tabular}


With the aim of additional inquiry into the association between the estimation of religious struggle and life satisfaction (H4), coping strategies were submitted as a prospective mediator between the independent variables (dimensions of religious strains) and the dependent variable (satisfaction with life). Tables 3-6 show the statistics concomitant with each mediation path.

Table 3. The role of coping strategies on religious comfort and life satisfaction $(\mathrm{N}=744)$.

\begin{tabular}{|c|c|c|c|c|c|c|}
\hline & a Path & b Path & c Path & $c^{\prime}$ Path & $\begin{array}{l}\text { Indirect Effect } \\
\text { and } B(S E)\end{array}$ & $\begin{array}{c}\text { 95\% CI LOWER } \\
\text { UPPER }\end{array}$ \\
\hline RE-AC-LS & $0.04 * *$ & $0.33^{* * *}$ & $0.11^{* * *}$ & $0.09 * * *$ & $0.0152(0.0053)$ & $0.0052 ; 0.0260$ \\
\hline RE-PL-LS & $0.03 *$ & $0.31^{* * *}$ & $0.11^{* * *}$ & $0.10^{* * *}$ & $0.0103(0.0051)$ & $0.0007 ; 0.0207$ \\
\hline RE-PR-LS & $0.09^{* * *}$ & $0.32^{* * *}$ & $0.11^{* * *}$ & $0.08^{* * *}$ & $0.0310(0.0060)$ & $0.0196 ; 0.0432$ \\
\hline RE-AA-LS & $0.04^{* *}$ & $0.23^{* * *}$ & $0.11^{* * *}$ & $0.10^{* * *}$ & $0.0100(0.0040)$ & $0.0028 ; 0.0184$ \\
\hline RE-HU-LS & $-0.04^{* *}$ & $0.10^{* *}$ & $0.11^{* * *}$ & $0.10^{* *}$ & $-0.0044(0.0023)$ & $-0.0098 ;-0.0007$ \\
\hline RE-ES-LS & $0.06^{* * *}$ & $0.32 * * *$ & $0.11^{* * *}$ & $0.09^{* * *}$ & $0.0025(0.0066)$ & $0.0100 ; 0.0354$ \\
\hline RE-IS-LS & $0.06^{* * *}$ & $0.22 * * *$ & $0.11^{* * *}$ & $0.09 * * *$ & $0.0138(0.0046)$ & $0.0051 ; 0.0238$ \\
\hline RE-SD-LS & $-0.06^{* *}$ & $-0.09 * *$ & $0.11^{* * *}$ & $0.10^{* * *}$ & $0.0061(0.0026)$ & $0.0017 ; 0.0120$ \\
\hline RE-VE-LS & $-0.03 *$ & -0.05 (n.s.) & $0.11^{* * *}$ & $0.11^{* * *}$ & $0.0022(0.0017)$ & $-0.0004 ; 0.0063$ \\
\hline RE-BD-LS & $-0.04 * *$ & $-0.35^{* * *}$ & $0.11^{* * *}$ & $0.09^{* * *}$ & $0.0157(0.0059)$ & $0.0047 ; 0.0278$ \\
\hline RE-DE-LS & $-0.05^{* *}$ & $-0.14^{* * *}$ & $0.11^{* * *}$ & $0.10^{* * *}$ & $0.0079(0.0031)$ & $0.0028 ; 0.0147$ \\
\hline RE-SA-LS & $-0.08^{* * *}$ & $-0.11^{* * *}$ & $0.11^{* * *}$ & $0.10^{* * *}$ & $0.0100(0.0034)$ & $0.0041 ; 0.0175$ \\
\hline RE-SB-LS & $-0.05^{* *}$ & $-0.30 * * *$ & $0.11^{* * *}$ & $0.09 * * *$ & $0.0157(0.0059)$ & $0.0047 ; 0.0278$ \\
\hline RE-RL-LS & $0.55^{* * *}$ & -0.00 & $0.11^{* * *}$ & $0.11^{* * *}$ & $-0.0028(0.0243)$ & $-0.0492 ; 0.0458$ \\
\hline
\end{tabular}

${ }^{*} p<0.05 ;{ }^{* *} p<0.01 ;{ }^{* * *} p<0.001$; n.s.-non-significant; RE-religious comfort; AC-active coping; LS-life satisfaction; PL-planning; PR-positive reframing; AA—acceptance; HU-humor; ES—emotional support; IS - instrumental support; SD—self distraction; VE—venting; $\mathrm{BD}$-behavioral disengagement; $\mathrm{DE}$ - denial; SA-substance abuse; SB-self-blame; RL-religious coping; a path = effect of the independent variable on the mediator; $\mathrm{b}$ path $=$ effect of the mediator on the dependent variable; $\mathrm{c}$ path $=$ effect of the independent variable on the dependent variable; $c^{\prime}$ path = direct effect of the independent variable on the dependent variable while controlling for the mediator.

Table 4. The role of coping strategies on fear/guilt and life satisfaction $(\mathrm{N}=744)$.

\begin{tabular}{|c|c|c|c|c|c|c|}
\hline & a Path & b Path & c Path & $c^{\prime}$ Path & $\begin{array}{l}\text { Indirect Effect } \\
\text { and } B(S E)\end{array}$ & $\begin{array}{c}\text { 95\% CI LOWER } \\
\text { UPPER }\end{array}$ \\
\hline FG-AC-LS & $-0.11^{* * *}$ & $0.33^{* * *}$ & $-0.13^{* * *}$ & $-0.09 * * *$ & $-0.0378(0.0089)$ & $-0.0562 ;-0.0212$ \\
\hline FG-PL-LS & $-0.11^{* * *}$ & $0.31^{* * *}$ & $-0.13^{* * *}$ & $-0.09 * * *$ & $-0.0354(0.0089)$ & $-0.0533 ;-0.0183$ \\
\hline FG-PR-LS & $-0.10^{* * *}$ & $0.32^{* * *}$ & $0.13^{* * *}$ & $-0.09^{* * *}$ & $-0.0345(0.0101)$ & $-0.0547 ;-0.0151$ \\
\hline FG-AA-LS & $-0.05 *$ & $0.23^{* * *}$ & $-0.13^{* * *}$ & $-0.11^{* * *}$ & $-0.0136(0.0065)$ & $-0.0271 ;-0.0014$ \\
\hline FG-HU-LS & 0.02 (n.s.) & $0.10^{* *}$ & $-0.13^{* * *}$ & $0.13^{* *}$ & $0.0024(0.0025)$ & $-0.0021 ; 0.0080$ \\
\hline FG-ES-LS & $-0.08^{* * *}$ & $0.32^{* * *}$ & $0.13^{* * *}$ & $-0.10^{* * *}$ & $-0.0285(0.0109)$ & $-0.0505 ;-0.0072$ \\
\hline FG-IS-LS & -0.04 (n.s.) & $0.22 * * *$ & $-0.13^{* * *}$ & $-0.12^{* * *}$ & $-0.0116(0.0075)$ & $-0.0266 ; 0.0029$ \\
\hline FG-SD-LS & $0.08^{* *}$ & $-0.09 * *$ & $-0.13^{* * *}$ & $0.12^{* * *}$ & $-0.0093(0.0041)$ & $-0.0186 ;-0.0026$ \\
\hline FG-VE-LS & $0.10^{* * *}$ & -0.05 (n.s.) & $0.13^{* * *}$ & $-0.12^{* * *}$ & $-0.0057(0.0044)$ & $-0.0151 ; 0.0025$ \\
\hline FG-BD-LS & $0.19^{* * *}$ & $-0.35^{* * *}$ & $-0.13^{* * *}$ & $-0.06^{* * *}$ & $-0.0693(0.0110)$ & $-0.0928 ;-0.0494$ \\
\hline FG-DE-LS & $0.10^{* * *}$ & $-0.14^{* * *}$ & $-0.13^{* * *}$ & $-0.11^{* * *}$ & $-0.0152(0.0051)$ & $-0.0265 ;-0.0066$ \\
\hline FG-SA-LS & $0.14^{* * *}$ & $-0.11^{* * *}$ & $-0.13^{* * *}$ & $-0.11^{* * *}$ & $-0.0185(0.0060)$ & $-0.0315 ;-0.0081$ \\
\hline FG-SB-LS & $-0.28 * * *$ & $-0.30 * * *$ & $-0.13^{* * *}$ & -0.04 (n.s.) & $-0.0089(0.0119)$ & $-0.1135 ;-0.0660$ \\
\hline FG-RL-LS & $0.27^{* * *}$ & -0.00 & $-0.13^{* * *}$ & $-0.18^{* * *}$ & $0.0529(0.0099)$ & $0.0352 ; 0.0748$ \\
\hline
\end{tabular}

${ }^{*} p<0.05 ;{ }^{* *} p<0.01 ;{ }^{* * *} p<0.001 ;$ n.s.—non-significant; FG-fear-guilt; AC-active coping; LS-life satisfaction; PL—planning; PR—positive reframing; AA—acceptance; HU—humor; ES—emotional support; IS—instrumental support; SD—self distraction; VE—venting; $\mathrm{BD}$ - behavioral disengagement; $\mathrm{DE}$-denial; SA—substance use; $\mathrm{SB}$ - self-blame; RL-religious coping; a path = effect of the independent variable on the mediator; $b$ path = effect of the mediator on the dependent variable; c path = effect of the independent variable on the dependent variable; $c^{\prime}$ path $=$ direct effect of the independent variable on the dependent variable while controlling for the mediator. 
Table 5. The role of coping strategies on negative emotions toward God and life satisfaction $(\mathrm{N}=744)$.

\begin{tabular}{|c|c|c|c|c|c|c|}
\hline & a Path & b Path & c Path & $c^{\prime}$ Path & $\begin{array}{l}\text { Indirect Effect } \\
\text { and B (SE) }\end{array}$ & $\begin{array}{c}\text { 95\% CI LOWER } \\
\text { UPPER }\end{array}$ \\
\hline NG-AC-LS & $-0.15^{* * *}$ & $0.29^{* * *}$ & $-0.24^{* * *}$ & $-0.20^{* * *}$ & $-0.0460(0.0093)$ & $-0.0656 ;-0.0289$ \\
\hline NG-PL-LS & $-0.09 * * *$ & $0.29 * * *$ & $-0.24^{* * *}$ & $-0.21^{* * *}$ & $-0.0292(0.0083)$ & $-0.0464 ;-0.0134$ \\
\hline NG-PR-LS & $-0.15^{* * *}$ & $0.31^{* * *}$ & $-0.24^{* * *}$ & $-0.19^{* * *}$ & $-0.0480(0.0100)$ & $-0.0689 ;-0.0291$ \\
\hline NG-AA-LS & $-0.11^{* * *}$ & $0.21^{* * *}$ & $-0.24^{* * *}$ & $-0.22^{* * *}$ & $-0.0244(0.0073)$ & $-0.0401 ;-0.0112$ \\
\hline NG-HU-LS & 0.06 * & $0.10^{* *}$ & $-0.24^{* * *}$ & $-0.25 * *$ & $0.0067(0.0044)$ & $-0.0004 ; 0.0166$ \\
\hline NG-ES-LS & $-0.12 * * *$ & $0.31^{* * *}$ & $-0.24^{* * *}$ & $-0.20^{* * *}$ & $-0.0396(0.0112)$ & $-0.0623 ;-0.0182$ \\
\hline NG-IS-LS & $-0.07 *$ & $0.23^{* * *}$ & $-0.24^{* * *}$ & $-0.23^{* * *}$ & $-0.0164(0.0074)$ & $-0.0312 ;-0.0022$ \\
\hline NG-SD-LS & $0.15^{* * *}$ & $-0.07 *$ & $-0.24^{* * *}$ & $-0.23^{* * *}$ & $-0.0117(0.0054)$ & $-0.0234 ;-0.0022$ \\
\hline NG-VE-LS & $0.14^{* * *}$ & -0.01 (n.s.) & $-0.24^{* * *}$ & $-0.24^{* * *}$ & $-0.0024(0.0055)$ & $-0.0136 ; 0.0085$ \\
\hline NG-BD-LS & $0.19^{* * *}$ & $-0.31^{* * *}$ & $-0.24^{* * *}$ & $-0.18^{* * *}$ & $-0.0630(0.0107)$ & $-0.0854 ;-0.0433$ \\
\hline NG-DE-LS & $0.16^{* * *}$ & $-0.11^{* * *}$ & $-0.24^{* * *}$ & $-0.22 * * *$ & $-0.0185(0.0065)$ & $-0.0323 ;-0.0072$ \\
\hline NG-SA-LS & $0.20 * * *$ & $-0.09 * * *$ & $-0.24^{* * *}$ & $-0.22^{* * *}$ & $-0.0191(0.0068)$ & $-0.0331 ;-0.0068$ \\
\hline NG-SB-LS & $0.21^{* * *}$ & $-0.27^{* * *}$ & $-0.24^{* * *}$ & $-0.18^{* * *}$ & $-0.0600(0.0109)$ & $-0.0824 ;-0.0395$ \\
\hline NG-RL-LS & $-0.41^{* * *}$ & $0.07^{* * *}$ & $-0.24^{* * *}$ & $-0.21^{* * *}$ & $-0.0323(0.0108)$ & $-0.0537 ;-0.0118$ \\
\hline
\end{tabular}

${ }^{*} p<0.05 ;{ }^{* *} p<0.01 ;{ }^{* * *} p<0.001 ;$ n.s.-non-significant; NG-negative emotions toward God; AC—active coping; LS—life satisfaction; PL—planning; PR—positive reframing; AA—acceptance; HU—humor; ES — emotional support; IS—instrumental support; $\mathrm{SD}$ — self distraction; VE—venting; $\mathrm{BD}$-behavioral disengagement; DE—denial; SA-substance abuse; SB - self-blame; RL-religious coping; a path = effect of the independent variable on the mediator; $\mathrm{b}$ path $=$ effect of the mediator on the dependent variable; $\mathrm{c}$ path $=$ effect of the independent variable on the dependent variable; $c^{\prime}$ path = direct effect of the independent variable on the dependent variable while controlling for the mediator.

Table 6. The role of coping strategies on negative social interactions surrounding religion and life satisfaction $(\mathrm{N}=744)$.

\begin{tabular}{|c|c|c|c|c|c|c|}
\hline & a Path & b Path & c Path & $c^{\prime}$ Path & $\begin{array}{c}\text { Indirect Effect } \\
\text { and } B(S E)\end{array}$ & $\begin{array}{c}\text { 95\% CI LOWER } \\
\text { UPPER }\end{array}$ \\
\hline NI-AC-LS & $-0.06^{* *}$ & $0.33^{* * *}$ & $-0.17^{* * *}$ & $-0.15^{* * *}$ & $-0.0207(0.0088)$ & $-0.0383 ;-0.0042$ \\
\hline NI-PL-LS & -0.02 (n.s.) & $0.33^{* * *}$ & $-0.17^{* * *}$ & $-0.16^{* * *}$ & $-0.0072(0.0083)$ & $-0.0233 ; 0.0092$ \\
\hline NI-PR-LS & $-0.08^{* * *}$ & $0.33^{* * *}$ & $-0.17^{* * *}$ & $-0.14^{* * *}$ & $-0.0213(0.0093)$ & $-0.0479 ;-0.0118$ \\
\hline NI-AA-LS & -0.01 (n.s.) & $0.25^{* * *}$ & $-0.17^{* * *}$ & $-0.16^{* * *}$ & $-0.0042(0.0062)$ & $-0.0172 ; 0.0078$ \\
\hline NI-HU-LS & $0.07^{* *}$ & $0.10^{* *}$ & $-0.24^{* * *}$ & $-0.18^{* *}$ & $0.0086(0.0037)$ & $0.0025 ; 0.0166$ \\
\hline NI-ES-LS & $-0.12^{* * *}$ & $0.32^{* * *}$ & $-0.17^{* * *}$ & $-0.13^{* * *}$ & $-0.0409(0.0105)$ & $-0.0629 ;-0.0217$ \\
\hline NI-IS-LS & -0.05 (n.s.) & $0.23^{* * *}$ & $-0.17^{* * *}$ & $-0.16^{* * *}$ & $-0.0130(0.0072)$ & $-0.0278 ; 0.0003$ \\
\hline NI-SD-LS & $0.13^{* * *}$ & $-0.09 * *$ & $-0.17^{* * *}$ & $-0.16^{* * *}$ & $-0.0119(0.0049)$ & $-0.0225 ;-0.0035$ \\
\hline NI-VE-LS & $0.13^{* * *}$ & -0.03 (n.s.) & $-0.17^{* * *}$ & $-0.16^{* * *}$ & $-0.0041(0.0052)$ & $-0.0148 ; 0.0057$ \\
\hline NI-BD-LS & $0.11^{* * *}$ & $-0.34 * * *$ & $-0.17^{* * *}$ & $-0.13^{* * *}$ & $-0.0411(0.0103)$ & $-0.0620 ;-0.0217$ \\
\hline NI-DE-LS & $0.12^{* * *}$ & $-0.13^{* * *}$ & $-0.17^{* * *}$ & $-0.15^{* * *}$ & $-0.0164(0.0054)$ & $-0.0282 ;-0.0071$ \\
\hline NI-SA-LS & $0.17^{* * *}$ & $-0.10^{* * *}$ & $-0.17^{* * *}$ & $-0.15^{* * *}$ & $-0.0194(0.0061)$ & $-0.0321 ;-0.0084$ \\
\hline NI-SB-LS & $0.21^{* * *}$ & $-0.28^{* * *}$ & $-0.17^{* * *}$ & $-0.11^{* * *}$ & $-0.0617(0.0098)$ & $-0.0821 ;-0.0433$ \\
\hline NI-RL-LS & $-0.36^{* * *}$ & $0.09^{* * *}$ & $-0.17 * * *$ & $-0.13^{* * *}$ & $-0.0361(0.0097)$ & $-0.0561 ;-0.0177$ \\
\hline
\end{tabular}

${ }^{*} p<0.05 ;{ }^{* *} p<0.01 ;{ }^{* * *} p<0.001 ;$ n.s.-non-significant; NI-negative social interactions surrounding religion; AC-active coping; LS-life satisfaction; PL-planning; PR-positive reframing; AA-acceptance; HU—humor; ES — emotional support; IS—instrumental support; SD—self distraction; VE—venting; BD—behavioral disengagement; DE-denial; SA—substance abuse; SB-self-blame; RL—religious coping; a path = effect of the independent variable on the mediator; $b$ path $=$ effect of the mediator on the dependent variable; $c$ path $=$ effect of the independent variable on the dependent variable; $c^{\prime}$ path = direct effect of the independent variable on the dependent variable while controlling for the mediator.

The findings, gained as a result of bootstrap sampling (5000), with a $95 \% \mathrm{CI}$, revealed a significant role of all coping strategies, except for (1) venting and religious coping in the association between religious comfort and life satisfaction (Table 3); (2) humor, instrumental support, and venting in the relationship between fear/guilt and life satisfaction (Table 4); (3) humor and venting in the relationship between negative emotions toward God and life satisfaction (Table 5); and (4) planning, active coping, 
instrumental support, and venting in the relationship between negative social interactions surrounding religion and satisfaction (Table 6).

According to the obtained results, it can be cautiously affirmed that all coping strategies were mediators at least once, except venting. In all cases where no mediation occurred, the CI enclosed a zero, indicating that the indirect effect was insignificant. In other cases, the $c$ path fell to $c^{\prime}$ as a consequence of containing the mediator.

\section{Discussion}

Only a few studies have assessed how religious/spiritual struggles are connected to positive dimensions of human life (Zarzycka and Puchalska-Wasyl 2019). Even less research has dealt with the mediation role of secular coping strategies and their effects on the interrelation between religious/spiritual struggle and life satisfaction. The effects of the current study largely confirm the adopted hypotheses, which are in line with previous studies.

The first finding (H1) that emerged from our study is that religious comfort positively correlated with satisfaction, while fear/guilt, negative emotions toward God, and negative social interactions involving religion were associated negatively with life satisfaction. Our outcomes mirror results obtained in some former studies (Ayele et al. 1999), showing that people who experienced intrinsic religious activity, such as prayer, meditation, or Bible reading, declared higher life satisfaction, even after controlling for age, gender, health, and marital status. They also confirm the widely accepted explanation that positive forms of religious coping, considered a kind of religious struggle, may contribute to psychological adjustment (Pargament et al. 2001) and indicate a secure and confiding relationship with God (Hebert et al. 2009). Moreover, experimental studies (Pirutinsky et al. 2019a) specified that individuals with more positive implicit and explicit attitudes toward God predicted higher life satisfaction. In other analyses (Pirutinsky et al. 2019b), attachment to God was found to be the strongest predictor of mental health among both more traditional and less traditional Jewish believers. It can be concluded that the awareness of being in a close relationship with God, based on trust and not fear or negative emotions, may lead to a sense of satisfaction with one's own life. Therefore, our results seem to be important because there are some outcomes that report null or even opposite associations between positive religiosity and adjustment (Park et al. 2018). In other studies (Hebert et al. 2009), negative religious coping predicted worse satisfaction after controlling for demographic covariates. In fact, the authors showed that people who perceived God as distant and who expressed anger toward God declared lower well-being over time. Thus, a less secure relationship with divinity, which is reflected through negative religious coping, may lead to a drop in life satisfaction.

The second finding (H2) shows that religious comfort was positively related to active and religious coping, planning, positive reframing, acceptance, and emotional and instrumental support. Simultaneously, religious comfort was negatively related to self-distraction, venting, behavioral disengagement, denial, substance abuse, self-blame, and humor. Similar outcomes were obtained by Umezawa et al. (2012), who found that conviction about divine control was positively associated with coping strategies with some specific approaches (positive reframing, planning, and active coping) in Latina, African American, and non-Hispanic White older women. In other studies (Krägeloh et al. 2012), religious coping was positively linked to five approach strategies (active coping, planning, positive reframing, emotional support, and instrumental support) and venting. It should be emphasized that in the current research, as many as seven out of eight coping dimensions, according to the two-dimensional model of Krohne (1993) and Roth and Cohen (1986), were positively correlated with religious comfort.

In terms of Hypothesis H3, the results largely confirmed our assumptions. Self-distraction, venting, behavioral disengagement, denial, substance abuse, self-blame, and religious coping correlated positively with fear/guilt, negative emotions toward God, and negative social interactions related to religion. Similar results were obtained by Ai et al. (2010), who found that spiritual struggle positively 
correlated with avoidant coping $(r=0.30, p=0.001)$. This result is quite understandable if we consider that spiritual strains indicate conflicts of values and beliefs and signal a decline in emotional functioning. In another study (Terreri and Glenwick 2013), negative religious coping was positively and significantly associated with cognitive and behavioral avoidant coping among adolescents. Moreover, both of these variables correlated negatively with their life satisfaction. Howell et al. (2015) found that parentally bereaved children in the adaptive functioning group had lower avoidant coping and higher scores on religiosity.

With respect to Hypothesis $\mathrm{H} 4$, the present study confirms to a large degree that different forms of secular coping strategies, except venting, can be potential mediators of the association between religious comfort/struggling and satisfaction. This might be related to the fact that satisfaction during the experience of dealing with substantial difficulties in one's goal-related efforts (Lazarus 1966) requires a process of executing an adequate response to a stressor. For example, Canada et al. (2006) found that the positive association between religiosity/spirituality and functional well-being and religiosity/spirituality and overall quality of life were mediated through the use of active coping in a group of women directly prior to a course of adjuvant chemotherapy for ovarian cancer. Similarly, Pérez et al. (2009) showed through a path model that acceptance coping mediated the relationship between spiritual striving, renamed from spiritual growth, and depressive symptoms. In another study, Parenteau et al. (2011) observed that individuals who retained negative emotions and felt as if they were being punished by God also engaged in negative cognitions, which in turn were related to negative psychological adjustment. Moreover, Nairn and Merluzzi (2003) noticed that non-religious self-efficacy was a mediating factor between religious coping and adjustment. Zwingmann et al. (2006) indicated that only depressive coping, as a non-religious coping style, completely mediated the relationship between religious coping and psychosocial outcomes of anxiety and depression. Another secular coping strategy, called active problem-focused coping, did not have such a mediating effect. In this sense, our study revealed that not only active coping, but also almost all "beneficial" and less adaptive types of coping strategies, mediated the relationship between religious/spiritual struggles and life satisfaction. Therefore, the presence of different secular strategies is not indifferent to the way that the religious and spiritual perception of the relation with God and religious community relates to the personal evaluation of someone's life.

\section{Limitations}

Given that the research was conducted through online forums, it cannot be assumed that it refers to the general Catholic community. Elderly and less well-educated people may be unlikely to use internet resources. It would be enriching to broaden the sample to a larger group of middle-age and older adults, as these respondents may live with their religious comfort and spiritual strains differently. Last, but not least, our mediatory analysis was performed using a cross-sectional strategy. In the future, it would be noteworthy to apply a longitudinal strategy to assure the cause-and-effect relationship between the variables. Despite some limitations, our research amplifies our understanding of the R/S struggles and life satisfaction relationship, mediated by "secular" coping strategies. It confirms that both religious and secular methods of experiencing different strains seem to coexist with multiple other strategies in the context of broadly understood life satisfaction.

Author Contributions: Conceptualization, M.S., Z.K.; data curation, M.S.; investigation, M.S., Z.K., R.S.; methodology, M.S., Z.K.; resources, M.S., Z.K., R.S.; writing-original draft, M.S., Z.K., R.S. All authors have read and agreed to the published version of the manuscript.

Funding: This research received no external funding.

Conflicts of Interest: The authors declare no conflicts of interest. 


\section{References}

Abu-Raiya, Hisham, Ali Ayten, Qutaiba Agbaria, and Mustafa Tekke. 2018. Relationships between religious struggles and well-being among a multinational Muslim sample: A comparative analysis. Social Work 63: 347-56. [CrossRef] [PubMed]

Abu-Raiya, Hisham, Kenneth I. Pargament, Neal Krause, and Gail Ironson. 2015. Robust links between religious/spiritual struggles, psychological distress, and well-being in a national sample of American adults. American Journal of Orthopsychiatry 85: 565-75. [CrossRef] [PubMed]

Ai, Amy Lee, Crystal L. Park, Bu Huang, Willard L. Rodgers, and Terrence N. Tice. 2007. Psychosocial mediation of religious coping styles: A study of short-term psychological distress following cardiac surgery. Personality and Social Psychology Bulletin 33: 867-82. [CrossRef] [PubMed]

Ai, Amy Lee, Kenneth I. Pargament, Hoa B. Appe, and Ziad Kronfol. 2010. Depression following open-heart surgery: A part model involving interleukin-6, spiritual struggle, and hope under preoperative distress. Journal of Clinical Psychology 66: 1057-75. [CrossRef] [PubMed]

Ayele, Hana, Thomas Mulligan, Sylvia Gheorghiu, and Carlos Reyes-Ortiz. 1999. Religious activity improves life satisfaction for some physicians and older patients. Journal of the American Geriatrics Society 47: 453-55. [CrossRef]

Bachman, Lyle F. 2004. Statistical Analyses for Language Assessment. New York: Cambridge University Press.

Baitar, Abdelbari, Frank Buntinx, Tine De Burghggraeve, Laura Deckx, Dirk Schrijvers, Hans Wildiers, and Marjan van den Akker. 2018. The influence of coping strategies on subsequent well-being in older patients with cancer: A comparison with 2 control groups. Psycho-Oncology 27: 864-70. [CrossRef]

Canada, Andrea L., Patricia A. Parker, Janet S. de Moor, Karen Basen-Engquist, Lois M. Ramondetta, and Lorenzo Cohen. 2006. Active coping mediates the association between religion/spirituality and quality of life in ovarian cancer. Gynecologic Oncology 101: 102-7. [CrossRef]

Carver, Charles S. 1997. You want to measure coping but your protocol's too long: Consider the brief COPE. International Journal of Behavioral Medicine 4: 92-100. [CrossRef]

Cassibba, Rosalinda, Sonia Papagna, Maria T. Calabrese, Elisabetta Costantino, Angelo Paterno, and Pehr Granqvist. 2014. The role of attachment to God in secular and religious/spiritual ways of coping with a serious disease. Mental Health, Religion \& Culture 17: 252-61.

Cohen, Jacob. 1988. Statistical Power Analysis for the Behavioral Sciences. New York: Routledge Academic.

Currier, Joseph M., Lisseth Rojas-Flores, Wesley H. McCormick, Josephine Hwang Koo, Laura Cadavid, Francis Alexis Pineda, Elisabet Le Roux, and Tommy Givens. 2019. Spiritual struggles and ministry-related quality of life among faith leaders in Colombia. Psychology of Religion and Spirituality 11: 148-56. [CrossRef]

Dardas, Lafeta A., and Muayyad M. Ahmad. 2013. Coping strategies as mediators and moderators between stress and quality of life among parents of children with autistic disorder. Stress $\mathcal{E}$ Health 31: 5-12.

Dezutter, Jessie, Laura Dewitte, Evalyne Thauvoye, and S. Siebrecht Vanhooren. 2017. Meaningful coping with chronic pain: Exploring the interplay between goal violation, meaningful coping strategies and life satisfaction. Scandinavian Journal of Psychology 58: 29-35. [CrossRef] [PubMed]

Diener, Ed, Robert A. Emmons, Randy J. Larsen, and Sharon Griffin. 1985. The Satisfaction with Life Scale. Journal of Personality Assessment 49: 71-75. [CrossRef] [PubMed]

Ellison, Christopher G., Qijuan Fang, Kevin J. Flannelly, and Rebecca A. Steckler. 2013. Spiritual struggles and mental health: Exploring the moderating effects of religious identity. International Journal for the Psychology of Religion 23: 214-29. [CrossRef]

Evans, Wyatt R., Melinda A. Stanley, Terri L. Barrera, Julie J. Exline, Kenneth I. Pargament, and Ellen J. Teng. 2018. Morally injurious events and psychological distress among veterans: Examining the mediating role of religious and spiritual struggles. Psychological Trauma: Theory, Research, Practice, and Policy 10: 360-67. [CrossRef]

Exline, Julie J., Ann Marie Yali, and William C. Sanderson. 2000. Guilt, discord, and alienation: The role of religious strain in depression and suicidality. Journal of Clinical Psychology 56: 1481-96. [CrossRef]

Exline, Julie J., Todd W. Hall, Kenneth I. Pargament, and Valencia A. Harriott. 2017. Predictors of growth from spiritual struggle among Christian undergraduates: Religious coping and perceptions of helpful action by God are both important. The Journal of Positive Psychology 12: 501-8. [CrossRef] 
Faul, Franz, Edgar Erdfelder, Albert-Georg Lang, and Axel Buchner. 2007. G*Power 3: A flexible statistical power analysis program for the social, behavioral, and biomedical sciences. Behavior Research Methods 39: 175-91. [CrossRef]

Ferris, Abbott L. 2002. Religion and the quality of life. Journal of Happiness Studies 3: 199-215. [CrossRef]

Fidell, Linda S., and Barbara G. Tabachnick. 2003. Preparatory Data Analysis. In Handbook of Psychology: Research Methods in Psychology. Edited by John A. Schinka, Wayne F. Velicer and Irving B. Weiner. Hoboken: John Wiley \& Sons, pp. 115-41.

García, Felipe E., Carmen Gloria Barraza-Peña, Anna Wlodarczyk, Marcela Alvear-Carrasco, and Alejandro Reyes-Reyes. 2018. Psychometric properties of the Brief-COPE for the evaluation of coping strategies in the Chilean population. Psicologia; Reflexão e Crítica 31. [CrossRef]

Hayes, Andrew F. 2013. Introduction to Mediation, Moderation, and Conditional Process Analysis: A Regression-Based Approach. New York: Guilford.

Hebert, Randy S., Elana Weinstei, Lynn M. Martire, and Richard Schulz. 2006. Religion, spirituality and the well-being of informal caregivers: A review, critique, and research prospectus. Aging and Mental Health 10: 497-520. [CrossRef]

Hebert, Randy, Bozena Zdaniuk, Richard Schulz, and Michael Scheier. 2009. Positive and negative coping and well-being in women with breast cancer. Journal of Palliative Medicine 12: 537-545. [CrossRef] [PubMed]

Hill, Peter C., and Kenneth I. Pargament. 2003. Advances in the conceptualization and measurement of religion and spirituality: Implications for physical and mental health research. American Psychologist 58: 64-74. [CrossRef] [PubMed]

Howell, Kathryn H., Danielle N. Shapiro, Christopher M. Layne, and Julie Kaplow. 2015. Individual and psychosocial mechanisms of adaptive functioning in parentally bereaved children. Death Studies 39: 296-306. [CrossRef] [PubMed]

Idler, Ellen L., Julie J. McLaughlin, and Stanislav Kasl. 2009. Religion and the quality of life in the last year of life. Journals of Gerontology Series B: Psychological Sciences and Social Sciences 64: 528-37. [CrossRef]

Johnston, Ron, Kelvyn Jones, and David Manley. 2018. Confounding and collinearity in regression analysis: A cautionary tale and an alternative procedure, illustrated by studies of British voting behaviour. Quality $\mathcal{E}$ Quantity 52: 1957-76.

Juczyński, Zygfryd, and Nina Ogińska-Bulik. 2009. Narzędzia pomiaru stresu i radzenia sobie ze stresem. Warszawa: Pracownia Testów Psychologicznych.

Juczyński, Zygfryd. 2001. Narzędzia pomiaru w promocji psychologii zdrowia. Warszawa: Pracownia Testów Psychologicznych.

Kim, Jung-Hyun, Jeong Yeob Han, Bret R. Shaw, Fiona McTavish, and David H. Gustafson. 2010. The roles of social support and coping strategies in predicting breast cancer patients' emotional well-being: Testing mediation and moderation models. Journal of Health Psychology 15: 543-52. [CrossRef]

Koenig, Harold G. 2009. Research on religion, spirituality, and mental health: A review. Canadian Journal of Psychiatry 54: 283-91. [CrossRef]

Krägeloh, Christian U., Penny Pei Minn Chai, Daniel Shephers, and Rex Billington. 2012. How religious coping is used relative to other coping strategies depends on the individual's level of religiosity and spirituality. Journal of Religion and Health 51: 1137-51. [CrossRef]

Krause, Neal, Kenneth I. Pargament, Peter C. Hill, and Gail Ironson. 2018. Assessing the role of race/ethnicity in the relationships among spiritual struggles, health, and well-being. American Journal of Orthopsychiatry 88: 132-41. [CrossRef] [PubMed]

Krause, Neal. 2003. Religious meaning and subjective well-being in late life. The Journals of Gerontology: Series B 58: 160-70. [CrossRef]

Krohne, Heinz Walter. 1993. Vigilance and cognitive avoidance as concepts in coping research. In Attention and Avoidance: Strategies in Coping with Aversiveness. Edited by Heinz Walter Krohne. Seattle: Hogrefe \& Huber, pp. 19-50.

Lakens, Daniël. 2013. Calculating and reporting effect sizes to facilitate cumulative science: A practical primer for t-test and ANOVAs. Frontiers in Psychology 4: 863. [CrossRef] [PubMed]

Lazarus, Richard S. 1966. Psychological Stress and the Coping Process. New York: McGraw-Hill.

Lazarus, Richard S., and Susan Folkman. 1984. Stress, Appraisal, and Coping. New York: Springer. 
Mahoney, Annette, and Annmarie Cano. 2014. Introduction to the special section on religion and spirituality in family life: Pathways between relational spirituality, family relationships and personal well-being. Journal of Family Psychology 28: 735-38. [CrossRef] [PubMed]

Marks, Loren D., and David C. Dollahite. 2011. Mining the meanings and pulling out the process from psychology of religion's correlation mountain. Psychology of Religion and Spirituality 3: 181-93. [CrossRef]

Marks, Loren D., David C. Dollahite, and Kaity Pearl Young. 2019. Struggles experienced by religious minority families in the United States. Psychology of Religion and Spirituality 11: 247-56. [CrossRef]

McDougle, Linsey, Sara Konrath, Marlene Walk, and Femida Handy. 2016. Religious and secular coping strategies and mortality risk among older adults. Social Indicators Research 125: 677-94. [CrossRef]

Mehmeoglu, Mehmet, and Tor Georg Jakobsen. 2017. Applied Statistics Using STATA: A Guide for the Social Sciences. London: SAGE Publications.

Nairn, Raymond C., and Thomas V. Merluzzi. 2003. The role of religious coping in adjustment to cancer. Psycho-Oncology 12: 428-41. [CrossRef] [PubMed]

Osborne, Jason W., and Amy Overbay. 2004. The power of outliers (and why researchers should always check for them). Practical Assessment, Research E Evaluation 9: 1-12.

Páez, Darío, Gonzalo Martínez-Zelaya, Marian Bilbao, Felipe E. García, Javier Torres-Vallejos, Salvador Vargas, Edgardo Sierralta, and Silvia da Costa. 2018. Religiosity, psychosocial factors, and well-being: An examination among a national sample of Chileans. Psychology of Religion and Spirituality 10: 138-45. [CrossRef]

Pakenham, Kenneth I. 2008. Making sense of caregiving for persons with multiple sclerosis (MS): The dimensional structure of sense making and relations with positive and negative adjustment. International Journal of Behavioral Medicine 15: 241-52. [CrossRef]

Parenteau, Stacy C., Nancy A. Hamilton, Wei Wu, Kevin Latinis, Lori B. Waxenberg, and Mary Y. Brinkmeyer. 2011. The mediating role of secular coping strategies in the relationship between religious appraisals and adjustment to chronic pain: The middle road to Damascus. Social Indicators Research 104: 407-25. [CrossRef]

Pargament, Kenneth I. 1997. The Psychology of Religion and Coping: Theory, Research, and Practice. New York: Guilford Press.

Pargament, Kenneth I. 2002. The bitter and the sweet: An evaluation of the costs and benefits of religiousness. Psychological Inquiry 13: 168-81. [CrossRef]

Pargament, Kenneth I., David S. Ensing, Kathryn Falgout, Hannah Olsen, Barbara Reilly, Kimberly Van Haitsma, and Richard Warren. 1990. God help me: (I): Religious coping efforts as predictors of the outcomes to significant negative life events. American Journal of Community Psychology 18: 793-824. [CrossRef]

Pargament, Kenneth I., Harold G. Koenig, Nalini Tarakeshwar, and June Hahn. 2001. Religious struggle as a predictor of mortality among medically ill elderly patients: A 2-year longitudinal study. Archives of Internal Medicine 161: 1881-85. [CrossRef] [PubMed]

Park, Crystal L., and Lawrence H. Cohen. 1993. Religious and nonreligious coping with the death of a friend. Cognitive Therapy and Research 17: 561-77. [CrossRef]

Park, Crystal L., Cheryl L. Holt, Daisy Le, Juliette Christie, and Beverly Rosa Williams. 2018. Positive and negative religious coping styles as prospective predictors of well-being in African Americans. Psychology of Religion and Spirituality 10: 318-26. [CrossRef]

Park, Crystal L., Harlow Jennifer Wortmann, and Donald Edmondson. 2011. Religious struggle as a predictor of subsequent mental and physical well-being in advanced heart failure patients. Journal of Behavioral Medicine 34: 426-36. [CrossRef]

Pérez, John E., Maggie Chartier, Cheryl Koopman, Mark Vosvick, Cheryl Gore-Felton, and David Spiegel. 2009. Spiritual striving, acceptance coping, and depressive symptoms among adults living with hiv/aids. Journal of Health Psychology 14: 88-97. [CrossRef]

Pirutinsky, Steven, Aaron D. Cherniak, and David H. Rosmarin. 2019a. Implicit and explicit attitudes towards God and life satisfaction. Psychology of Religion and Spirituality. [CrossRef]

Pirutinsky, Steven, David H. Rosmarin, and Lee A. Kirkpatrick. 2019b. Is attachment to God a unique predictor of mental health? Test in a Jewish sample. The International Journal for the Psychology of Religion 29: 161-71. [CrossRef]

Pruchno, Rachel A., and Nancy L. Resch. 1989. Mental health of caregiving spouses: Coping as mediator, moderator, or main effect? Psychology and Aging 4: 454-463. [CrossRef] 
Roth, Susan, and Lawrence J. Cohen. 1986. Approach, avoidance, and coping with stress. American Psychologist 41: 813-19. [CrossRef] [PubMed]

Salifu Yendork, Joana, and Nceba Z. Somhlaba. 2017. I am happy because of God": Religion and spirituality for well-being in Ghanaian orphanage-placed children. Psychology of Religion and Spirituality 9: 32-39. [CrossRef]

Sasaki, Joni Y., and Heejung S. Kim. 2011. At the intersection of culture and religion: A cultural analysis of religion's implications for secondary control and social affiliation. Journal of Personality and Social Psychology 101: 401-14. [CrossRef] [PubMed]

Sawatzky, Rick, Pamela A. Ratner, and Lyern Chiu. 2005. A meta-analysis of the relationship between spirituality and quality of life. Social Indicators Research 72: 153-88. [CrossRef]

Stauner, Nick, Julie J. Exline, Jessica R. Kusina, and Kenneth I. Pargament. 2019. Religious and spiritual struggles, religiousness, and alcohol problems among undergraduates. Journal of Prevention $\mathcal{E}$ Intervention in the Community 47: 243-58.

Szcześniak, Małgorzata, Grażyna Bielecka, Iga Bajkowska, Anna Czaprowska, and Daria Madej. 2019. Religious/spiritual struggles and life satisfaction among young Roman Catholics: The mediating role of gratitude. Religions 10: 395. [CrossRef]

Terreri, Cydney J., and David S. Glenwick. 2013. The relationship of religious and general coping to psychological adjustment and distress in urban adolescents. Journal of Religion and Health 52: 1188-202. [CrossRef]

Trevino, Kelly M., Kenneth I. Pargament, Neal Krause, Gail Ironson, and Peter Hill. 2019. Stressful events and religious/struggle: Moderating effects of the general orienting system. Psychology of Religion and Spirituality 11: 214-24. [CrossRef]

Turska-Kawa, Agnieszka, and Waldemar Wojtasik. 2017. Diversity of Roman Catholics in Poland and Their Socio-Institutional Preferences. Religio 25: 43-68.

Umezawa, Yoshiko, Qian Lu, Jin You, Marjorie Kagawa-Singer, Barbara Leake, and Rose C. Maly. 2012. Belief in divine control, coping, and race/ethnicity among older women with breast cancer. Annals of Behavioral Medicine 44: 21-32. [CrossRef]

Van Tongeren, Daryl R., Joshua N. Hook, and Don E. Davis. 2013. Defensive religion as a source of meaning in life: A dual mediational model. Psychology of Religion and Spirituality 5: 227-32. [CrossRef]

Vandecreek, Larry, Stephen A. Paget, Roberta Horton, Laura Robbins, Margaret Oettinger, and Katie Tai. 2004. Religious and nonreligious coping methods among persons with rheumatoid arthritis. Arthritis $\mathcal{E}$ Rheumatism 51: 49-55.

Vasegh, Sasan, David H. Rosmarin, Harold G. Koenig, Rachel E. Dew, and Raphael M. Bonelli. 2012. Religious and spiritual factors in depression. Depression Research and Treatment, 298056. [CrossRef] [PubMed]

Williams, Paula G., Deborah J. Wiebe, and Timothy W. Smith. 1992. Coping processes as mediators of the relationship between hardiness and health. Journal of Behavioral Medicine 15: 237-55. [CrossRef] [PubMed]

Wilt, Joshua A., Joshua B. Grubbs, Julie J. Exline, and Kenneth I. Pargament. 2016. Personality, religious and spiritual struggles, and well-being. Psychology of Religion and Spirituality 8: 341. [CrossRef]

Wilt, Joshua A., Joshua B. Grubbs, Kenneth I. Pargament, and Julie J. Exline. 2017. Religious and spiritual struggles, past and present: Relations to the Big Five and well-being. International Journal for the Psychology of Religion 27: 51-64. [CrossRef]

Wilt, Joshua A., Kenneth I. Pargament, and Julie J. Exline. 2019a. The transformative power of the sacred: Social, personality, and religious/spiritual antecedents and consequents of sacred moments during a religious/spiritual struggle. Psychology of Religion and Spirituality 11: 233-46. [CrossRef]

Wilt, Joshua A., Nick Stauner, Valencia A. Harriott, Julie J. Exline, and Kenneth I. Pargament. 2019b. Partnering with God: Religious coping and perceptions of Divine intervention predict spiritual transformation in response to religious-spiritual struggle. Psychology of Religion and Spirituality 11: 278-90. [CrossRef]

Zarzycka, Beata, and Małgorzata M. Puchalska-Wasyl. 2019. Can religious and spiritual struggle enhance well-being? Exploring the mediating effects of internal dialogues. Journal of Religion and Health. [CrossRef]

Zarzycka, Beata, and Paweł Zietek. 2019. Spiritual growth or decline and meaning-making as mediators of anxiety and satisfaction with life during religious struggle. Journal of Religion and Health 58: 1072-86. [CrossRef]

Zarzycka, Beata. 2014. The internal structure of the Polish adaptation of The Religious Comfort and Strain Scale. Annals of Psychology 17: 697-710. 
Zhang, Hansong, Joshua N. Hook, Jennifer E. Farrell, David K. Mosher, Daryl R. Van Tongeren, and Don E. Davis. 2018. The effect of religious diversity on religious belonging and meaning: The role of intellectual humility. Psychology of Religion and Spirituality 10: 72-78. [CrossRef]

Zinnbauer, Brian J., and Kenneth I. Pargament. 1998. Spiritual conversion: A study of religious change among college students. Journal for the Scientific Study of Religion 37: 161-80. [CrossRef]

Zwingmann, Christian, Markus Antonius Wirtz, Claudia Müller, Jürgen Körber, and Sebastian Murken. 2006. Positive and negative religious coping in German breast cancer patients. Journal of Behavioral Medicine 29: 533-47. [CrossRef] [PubMed]

(C) 2020 by the authors. Licensee MDPI, Basel, Switzerland. This article is an open access article distributed under the terms and conditions of the Creative Commons Attribution (CC BY) license (http://creativecommons.org/licenses/by/4.0/). 